\title{
ODOROUS EMISSION REDUCTION FROM A WASTE LANDFILL WITH AN OPTIMAL PROTECTION SYSTEM BASED ON FUZZY LOGIC
}

\author{
Armando Di Nardo ${ }^{\mathrm{a},}{ }^{*}$, Immacolata Bortone $^{\mathrm{b}}$, Simeone Chianese ${ }^{\mathrm{a}}$, Michele Di Natale ${ }^{\mathrm{a}}$, Alessandro Erto ${ }^{\mathrm{c}}$, Giovanni \\ Francesco Santonastaso $^{\text {a }}$, Dino Musmarra ${ }^{a}$
}

\begin{abstract}
aDipartimento di Ingegneria, Università degli Studi della Campania "Luigi Vanvitelli”, Via Roma 29, 81031, Aversa (CE), Italy.

bSchool of Water, Energy and Environment, Cranfield University, College Road, Cranfield, United Kingdom.

${ }^{\mathrm{c} D i p a r t i m e n t o ~ d i ~ I n g e g n e r i a ~ C h i m i c a, ~ d e i ~ M a t e r i a l i ~ e ~ d e l l a ~ P r o d u z i o n e ~ I n d u s t r i a l e, ~ U n i v e r s i t a ̀ ~ d i ~ N a p o l i ~ F e d e r i c o ~}$ II, P.le Tecchio, 80, 80125, Napoli, Italy.
\end{abstract}

\begin{abstract}
Effective landfill management and operation require an accurate evaluation of the occurrence and extent of odour emission events, which are among the main causes of resident complaints and concerns, in particular in densely urbanised areas. This paper proposes a Fuzzy Optimal Protection System (FOPS) based on fuzzy logic to manage odour production from a Municipal Solid Waste (MSW) landfill. The case study is a MSW landfill in an old quarry site located $6 \mathrm{~km}$ north-west of Naples city centre (Italy). The aim is to reduce the odour nuisance in the area surrounding the landfill where there are several sensitive receptors. FOPS is based on logical relationships between local atmospheric dynamics, number and intensity of odour pollution events detected by certain fixed receptors and odour emission rate via an optimal fuzzy approach. Such system allows to start, in real time, established mitigation actions required to further reduce the odorous emissions from the landfill itself (e.g., spraying of perfumed substances, activation of extraction wells, etc.), especially when weather conditions might not be favourable and cause a higher odour perception. The fuzzy system was coupled with the air pollutant transport software CALPUFF to simulate the odour dispersion in the considered area taking into account both different odour emission rates and local weather conditions. FOPS results show that this approach can be very useful as, by measuring the odour concentrations, a significant reduction of the odour exceedances over the thresholds fixed, to minimise the olfactory harassment, was observed in the whole area studied.
\end{abstract}

*Corresponding author: Armando Di Nardo, Dipartimento di Ingegneria, Università degli Studi della Campania “L. Vanvitelli”, Via Roma 9, 81031, Aversa (CE), Italy. Tel.: +39 0815010202; fax: +39 0815010436. E-mail address: armando.dinardo@unicampania.it (Armando Di Nardo)

\section{Keywords}

solid waste odour management; early warning system; odour; fuzzy logic; decision support system 


\section{Introduction}

All waste treatment and disposal facilities are potential sources of odours. Odours associated with waste landfills are listed among the most aggressive for human perception and consequently the most troublesome (Aatamila et al. 2010; De Feo,et al. 2013). They are primarily due to the biological and chemical decomposition processes taking place in the landfilled waste mass, but can be also originated from a site operational and waste management activities occurring both before and after waste burying (Fang et al. 2013; Lou et al. 2015). In particular, odour emissions in a waste landfill are associated to those areas where waste is not covered, such as where waste is delivered and moved, to the delays in burying the waste masses, to the trenching into covered waste to install biogas collection pipework and the low effectiveness of the bio-gas extraction system, as well as, the recirculation of the landfill leachate (U.S.EPA 1995a; EPA-Ireland 2000, Brattoli et al., 2011).

Odours and gas emissions can be formed by a single chemical compound such as hydrogen sulphide $\left(\mathrm{H}_{2} \mathrm{~S}\right)$ or more frequently by a complex mixture of organic compounds (Young and Parker 1983; Chianese et al. 2015). These are dispersed in air either as a gas or as small particles spread in the atmosphere as discrete compounds or attached to other particulate (Fabbri et al. 2014). In addition, odorous emissions can change continuously flow rate and concentration and might be characterised by alternation of long or short periods of high and low emissions, also depending on meteorological conditions (Drew et al. 2007). Continuous releases of low concentration odours can be as unpleasant as intermittent releases of odours at high concentrations, in terms of nuisance for the population, because cumulative effects of annoyance events are possible over an extended time exposure (Daskalopoulos et al. 1997; Meišutovič-Akhtarieva and Marčiulaitienè, 2017).

Since odour emissions, generated by a solid waste landfill, are multi source and strongly dependent on the local weather conditions, the consequent annoyance is difficult to predict. Therefore, an effective way to control the odour impact could be a direct intervention on all potential odour emission sources in the landfill, aimed at reducing the odour emission rates. In this way it is also possible to limit the extent of the offsite odour diffusion related to air transport, and indirectly prevent the exposure of potential sensitive receptors.(U.S.EPA 1995a, b).

In this context, the application of design and management of mitigation measures can reduce the diffusion of odours and the associated risk. Some mitigation measures might be a fast burying of waste, increasing the thickness of cover materials, improving the efficiency of the gas management system, using bio-filters or odour neutralising techniques, etc. (Chung et al. 2007; Chen et al. 2009; Erto et al. 2009; Karatza et al. 2010).

In the last few years the scientific community has focused their attention on coupling waste disposals management with appropriate Decision Support Systems (DSS), such as fuzzy systems. DSS have high potential to manage complex models where the amount of input and output data could not be analytically captured or controlled with conventional sense (Dokas and Panagiotakopoulos 2006; Dokas et al. 2009; Zhang and Huang 2010; Fan et al. 2014). In particular, some authors have applied fuzzy logic to solve problems arising from waste landfill emissions with a multi-criteria approach (Akbari et al. 2008; Singh and Vidyarthi 2008; Chang and Lin 2013). Some others have proposed a Landfill Operation Management Advisor based on different approaches and technologies (fault tree analysis, fuzzy expert systems and Worldwide Web) to provide assistance to landfill managers facing operational problems (Dokas et al. 2008, 2009). In addition, a fuzzy logic approach was also used to define the 
main objective functions in optimization problems applied to air quality management (Xu and Huang 2015) and air pollution abatement strategy under uncertainty (Li et al. 2008).

Furthermore, systems based on fuzzy logic can be very effective in nonlinear models and be a valid support where heuristic rules have to be considered (Di Nardo et al. 2013a, b).

In this paper, an optimal fuzzy logic system, called Fuzzy Optimal Protection System (FOPS), is proposed. The aim is to simulate a real time decision making system able to suggest the activation of some odorous emission mitigation actions, when it is needed, based on local meteorological input data. For this purpose a MSW landfill located in an area located north of Naples (Italy) was examined as case study and in particular three Sensitive Odour Receptors (SORs) were considered. These are located respectively north-east (NE), north-west (NW) and west-west-south (WWS) of the landfill, with a distance ranging from $800 \mathrm{~m}$ to $1.500 \mathrm{~m}$. For these receptors the odour concentrations were hourly evaluated and compared with two Odour Thresholds (OT) describing odour annoyance and nuisance at the receptors exposed. The number of threshold exceedances for each receptor was evaluated with and without using the FOPS system: this demonstrated that the application of FOPS allows for a further reduction of both number and extent of exceedances.

\section{Material and Methods}

FOPS system can assess in real time the necessary reduction of odorous emission from a landfill, obtained via using mitigation actions (e.g. activation of the extraction systems for the biogas and/or of the nebulisation systems). In this way, it is possible to cope with annoying odours also when severe adverse weather conditions occur.

A simplified scheme of FOPS is reported in Fig. 1. As shown, if the odour plume does not affect the target, FOPS is not enabled (Fig. 1a); on the contrary if the target is affected by the odour plume, FOPS is enabled (Fig. 1b) and the odour emission radically reduced.

Fig. 1 FOPS operation condition: (a) non-active status; (b) active status

A preliminary version of FOPS, called Smart Fuzzy System (SFS), was presented by Di Nardo et al. (2013b). Specifically, in FOPS, the fuzzy inference is significantly improved via an optimization of the fuzzy rule system, in this way increasing the risk mitigation from odour exposures for the population in the area surrounding the landfill (Wang and Huang 2013, 2015). The proposed procedure was implemented in a MATLAB framework by coupling the FUZZY LOGIC toolbox and the OPTIMIZATION Toolbox (The MathWorks Inc. 2004a , 2004b). Starting from 13 rules based on human expertise, the input variables of FOPS were defined via optimizing multiple "membership functions" as input and the individuated mitigation actions for landfills as output. A Genetic Algorithm (GA) was used as optimization algorithm; specifically, in order to preserve the physical importance of all the parameters considered, some constraints in GA were adopted. Finally, CALPUFF software, in which a dispersion puff model is implemented (U.S.EPA 1995c; Scire et al. 2000), was used to predict the odorous emission 
exposure over time in some defined targets, defined Sensitive Receptors, as already proposed in other studies (Hriberšek et al. 2011).

\subsection{Optimal Early Warning Fuzzy System}

Fuzzy systems are built on the fuzzy logic theory and provide a rigorous framework to represent non-crisp situations and to examine problems with uncertainty and non-linearity (Dubois and Prade 1980). The fuzzy approach allows for high flexibility and effectiveness, as it is possible to combine several rules simultaneously. These systems can be utilised for many different applications, including process control, decision-making, scheduling, prediction and estimation (Shill et al. 2012).

The fuzzy system is traditionally represented via four main steps (Fig. 2). The first step is called Fuzzification, which consists in transforming the numeric input data (crisp) into linguistic values by assigning a fuzzy set (linguistic variables) expressed via verbal phrases (e.g. "Very Good", "Bad", etc.). The individual elements of the set are labelled via Memberships Functions (MFs). The MFs can have several shapes, which influence differently the "weighting" of the input values in the range of definition. Consequently these values are processed in the fuzzy domain by the Inference algorithm. The Inference is the engine of the system; in which the decision-making is refined as fuzzy output according to a rule base provided by the Knowledge Base (KB) (Di Nardo et al. 2013b). The rules are provided as IF-THEN control rules and fuzzy logic operators (AND or OR). The IF-THEN rules link to an antecedent part (i.e. IF) containing several preconditions and a consequent part (i.e. THEN) describing the output action. Finally, the crisp output values are determined via the Defuzzification process, which translates the inference process conclusions into numerical values, providing a basis for the decision-making (Khalsa 2009). In Fig. 2 the phases considered to optimize the Fuzzy Optimal Protection System (FOPS) are shown, where the input variables affecting the System and the odour dispersion phenomena to a greater extent are also specified.

Fig. 2 Optimal FOPS Scheme with a description of input (Wind Speed, Time Derivative Velocity, Wind Direction) and output variable (Odour Emission Rate) and the corresponding sets of linguistic attribute $\left(\mathrm{P}_{1}, \mathrm{P}_{2}, \mathrm{P}_{3}\right.$ and $\left.\mathrm{C}_{1}\right)$

The type of fuzzy Inference System implemented was the Sugeno-type (Sugeno 1985), which was obtained by using the following $l$-th fuzzy rule $\mathrm{R}$, where $l=1, \ldots 13$ rules:

$$
R^{(l)}: \operatorname{IF} x_{1} \text { is } P_{1}^{(l)} A N D x_{2} \text { is } P_{2}^{(l)} \text { and } x_{3} \text { is } P_{3}^{(l)} \text { THEN } y=C_{1}
$$

in which:

- $x_{i} \in U_{i} \subset R$ are the physical measures affecting the dispersion of pollutants in the atmosphere, specifically $\mathrm{x}_{1}=$ Wind Speed (WS), $\mathrm{x}_{2}=$ Time Derivative of Velocity (TDV) and $\mathrm{x}_{3}=$ Wind Direction (WD);

- $\quad P^{(l)}{ }_{i}$ is the fuzzy set considered, which was referred to the $i$-th input linguistic variable, where $\mathrm{i}=1, \ldots, 3$, each at different levels. Specifically, $\mathrm{P}_{1}=\{$ Weak, Normal, Strong $\}, \mathrm{P}_{2}=\{$ Low, Zero, High $\}, \mathrm{P}_{3}=\{$ North, North-East (N-E), East, South-East (S-E), South, South-West (S-W), West, North-West (N-W)\}; 
- $y \in S \subset R$ is the output linguistic variable. This output variable allows to hourly reduce the odorous emissions via activating one or more of the expedients presented in the previous section. In particular, $y$ is a multiplier (crisp value) of the 1 -th rule, while $1=1, \ldots, 4$ is the Sugeno output set (Sugeno 1985) in which a singleton membership function can be equal to $C_{l}=\{$ Normal, Bad, Very Bad $\} . C_{1}$ elements correspond, respectively, to the following odour emission rates: Normal $=8$ o.u. $/ \mathrm{m}^{2} \mathrm{~s}, \mathrm{Bad}=4$ o.u. $/ \mathrm{m}^{2} \mathrm{~s}$, Very $\mathrm{Bad}=2$ o.u. $/ \mathrm{m}^{2} \mathrm{~s}$.

In this way, a possible decision rules system can be written as follows:

$$
R^{(l)}: I F W S \text { is normal ANDTDVis high ANDWD is } N-W \text { THENC }=\operatorname{Bad}(C)
$$

The rule represented in Equation (2) explains a situation where the "Wind Speed, WS" is "Normal, N", the "Time Derivative of Velocity, TDV" is "High, H" and the "Wind Direction, WD" is "North-West, N-W", then the odour "Concentration, $\mathrm{C}$ " is considered "Bad" and consequently the output emission rate is equal to 4 o.u. $/ \mathrm{m}^{2} \mathrm{~s}$.

The number of rules and MFs must reasonably be small, although, as reported in Panigrahi and Mujumdar (2000) by increasing them, a greater accuracy can be obtained but, as a consequence, the dimensionality of the optimization problems can significantly increase. This balancing between rules and MFs is essential to develop an effective fuzzy decision system. Starting from statistical data, multiple ways can be followed to build an optimal fuzzy system, which can be based on stochastic approach, neural clustering or heuristically from expert knowledge (Cavallo et al. 2013). In addition, more input linguistic variables and fuzzy sets could be adopted. In the present paper case study, the most important variables and sets were chosen and modelled also in compliance with the available data.

The rules and the shapes of the Membership Functions (MFs) chosen are reported in Table 1 and Fig. 3, respectively. The values of wind speed reported in Figure 3a are normalized used as Gaussian variable.

Table 1 System of fuzzy rules: $P_{1}, P_{2}, P_{3}$ and $C_{1}$ are the set of linguist attributes of Wind Speed, Time Derivative of Velocity, Wind Direction and Odour Emission Rate respectively.

Fig. 3 Optimized Membership Functions of FOPS: (a) Wind Speed (WS); (b) Time Derivative of the Velocity (TDV); (c) Wind Direction (WD)

A first choice of the rule Inference system and the MFs shape were defined empirically via a "trial and error" simulation method, starting from previous preliminary results obtained by using an empirical knowledge of the problem (Di Nardo et al. 2013b). In order to improve the heuristic strategy adopted, the optimization was achieved for $11 \alpha_{i}$ parameters of the input MFs (without the optimization of the fuzzy set $\mathrm{P}_{3}$ ) with a Genetic Algorithm (Goldberg 1989; Qin et al. 2010). Specifically, all the considered variables (both input and output) are described in the following:

- the Wind Speed was inserted $d$ in the input fuzzy set called $\mathrm{P}_{1}$, by considering three possible intensities ("Weak", "Normal" and "Strong") of MFs, six parameters $\alpha_{i}$ for $\mathrm{i}=1 \ldots 6$, two for each MF respectively (the two parameters for each intensity correspond to the mean and the variance of the curves adopted); 
- the Time Derivative of Wind Velocity was enclosed in the input fuzzy set called $\mathrm{P}_{2}$, via considering the three possible intensities of MFs: "Low", "High" and "Zero". "Low" and "High" depend on four parameters $\alpha_{i}$ for $\mathrm{i}=7 \ldots 10$ (the two parameters correspond to the mean and the variance of the MFs curves adopted), and "Zero", depends on a single $\alpha_{l l}$ parameter (its centre is fixed to the value 0 , only the variance is considered as a parameter);

Starting from the rule set shown in Table 1, the optimization, carried out with GA, provided as input the MFs showed in Fig. 3a, 3b and 3c.

In order to preserve a linguistic meaning of the fuzzy rules, it was chosen to adopt a constrained optimization (Cavallo et al. 2013) as presented in Table 1 (where for example, to constrain all variables and to avoid that a MF labelled "High" comes "before" (i.e., it is associated to smaller numerical values), a MF labelled "Low" was necessary). Consequently some upper and lower bounds (based on the available meteorological data) were imposed to the following $\alpha_{i}$ parameters, describing the MFs of the $P_{1}$ and $P_{2}$ input fuzzy sets: $-10 \leq \alpha_{1} \leq 10,-10 \leq \alpha_{2} \leq 10$, $0.1 \leq \alpha_{3} \leq 5,-1 \leq \alpha_{4} \leq 0,-10 \leq \alpha_{5} \leq 10,-10 \leq \alpha_{6} \leq 10,-1 \leq \alpha_{7} \leq 1,-1 \leq \alpha_{8} \leq 1,-1 \leq \alpha_{9} \leq 1,-1 \leq \alpha_{10} \leq 1.0 .1 \leq \alpha_{11} \leq 1$.

In this way, the linguistic meaning of the fuzzy rules is preserved as each attribute of the fuzzy set is different from the others and there are no numerical overlaps between the sets. It is worth highlighting that the choice of the values to assign to the bounds required a trial and error approach (Cavallo et al. 2013), with a consequential optimization.

The optimization was achieved by minimising the Multi Objective Function $(M O F)$ written as follows (Eq. 3):

$$
M O F=k_{1} \cdot \frac{C_{F O P S}}{C_{\text {cost }}}+k_{2} \cdot I_{a}
$$

where $C_{F O P S}$ and $C_{\text {cost }}$ are the olfactory concentrations, both computed via CALPUFF (described in Paragraph 3). $C_{F O P S}$ was obtained by considering the odour emission factors obtained with FOPS, while $C_{\text {cost }}$ by considering an emission constantly equal to 8 o.u. $/ \mathrm{m}^{2} \mathrm{~s}$ (Sironi et al. 2005), which corresponds to a landfill average emission without any mitigation action applied. Furthermore, two integer weights $\left(k_{l}=2\right.$ and $\left.k_{2}=1\right)$ were used to balance the two terms of MOF and to avoid the optimization of only one element. Finally, $I_{a}$ represents the activation index equal to (Eq. 4):

$$
I_{a}=\frac{N_{a}}{N_{h}}
$$

where $N_{a}$ is the number of FOPS system activations (the number of times in which FOPS operates with an odour reduction by adopting one or more mitigation actions) and $N_{h}$ is the total number of hours in the time simulation period.

It is worth observing that, with the use of the two integer weights $\left(\mathrm{k}_{1}\right.$ and $\left.\mathrm{k}_{2}\right)$ to balance the two addends of the MOF assumptions (Eq. 3), it is possible to normalize the terms of MOF using, consequently, the approach known as the "scalarization" or "weighted-sum" method that, as reported in Caramia and Dell'Olmo (2008) allows to define, starting from the multiobjective optimization problem, a unique objective function composed by two or more functions. 
The optimization is achieved by using a GA with 50 generations, a population composed of 50 individuals and a crossover percentage equal to $P_{\text {cross }}=0.8$.

In order to evaluate the effectiveness of the FOPS system, a reduction Index, $I_{r}$, was also calculated as in (Eq. 5):

$$
I_{r}=\frac{C_{\text {cost }}-C_{F O P S}}{C_{\text {cost }}}
$$

\subsection{Odour dispersion model}

Odorous substances are considered as atmospheric pollutants. Therefore their transport in the atmosphere can be described via deterministic models modelling air pollutants dispersion (Hobbs et al. 2000). In the present study, odour transport in the area surrounding a MSW landfill was modelled by using CALPUFF (Scire et al. 2000). Such software allows simulating a puff transport emitted from one or more sources, in a non-steady-state Gaussian puff modelling system, also considering dispersion and reaction processes occurring during the puff transport itself (Poor et al. 2006). The equation used for the contribution of a puff at a defined receptor, which is also the main CALPUFF formulation, is written as (Eq. 6):

$$
C=\frac{Q}{2 \pi \sigma_{x} \sigma_{y}} g \exp \left[\frac{-d_{a}^{2}}{2 \sigma_{x}^{2}}\right] \exp \left[\frac{-d_{c}^{2}}{2 \sigma_{y}^{2}}\right]
$$

Where:

$C$ is the ground level concentration expressed in $\mathrm{g} / \mathrm{m}^{3}$;

$Q$ is the mass of pollutant;

$\sigma_{x}$ and $\sigma_{y}$ are the standard deviation in $m$ of the Gaussian distribution in the along-wind direction and in the crosswind direction, respectively;

$d_{a}$ and $d_{c}$ are the distance from the puff centre to the receptor in the along-wind direction and in the cross wind direction, respectively.

The term $g$ is the vertical term of the Gaussian equation described as follows (Eq. 7):

$$
g=\frac{2}{(2 \pi)^{1 / 2} \sigma_{z}} \sum_{n=-\infty}^{\infty} \exp \left[\frac{-\left(H_{e}+2 n h\right)^{2}}{2 \sigma_{z}^{2}}\right]
$$

In (Eq.7), $H_{e}$ is the actual height above the ground of the puff centre and $h$ is the mixed-layer height and $\sigma_{z}$ is the standard deviation in $m$ of the Gaussian distribution in the vertical direction. The outline in the vertical term $g$ accounts for multiple reflections off mixing lid and ground. In order to predict the odour air dispersion, the local meteorological information of the area is needed. The assumptions made for this latter are reported in the Case study- section.

\section{Case study}

The FOPS system was applied to a MSW landfill located in an old quarry site named "Cava del Cane", in Naples (Italy). The quarry falls within the perimeter of the restricted territory of the "Chiaia's Forest - Selva di Chiaia", 
which is one of the areas of the Metropolitan Park of Naples Hills and includes over 2,215 acres of farmlands and natural areas in Northwest Naples. The position of the quarry is represented in Fig. 4. It has a surface of 12,450 $\mathrm{m}^{2}$ with a height of approximately $25 \mathrm{~m}$ (Bortone et al. 2012).

As depicted in Fig. 4, the area around the landfill is densely urbanised, and several sensitive receptors such as villages, schools, hospitals, leisure and sports centres are located nearby. In particular, three Sensitive Odour Receptors (SORs) were identified in the area of interest for their proximity to the landfill and the risk exposure to odours, called SOR-1:"Monaldi" hospital; SOR-2:"Marano" school; and SOR-3:"Kennedy" sports complex. These are respectively at $800 \mathrm{~m}, 1,300 \mathrm{~m}$ and 1,500 $\mathrm{m}$ from the landfill (Fig. 4).

Fig. 4 Case-study area with landfill and Sensitive Odour Receptors (SORs) positioning

In order to model the odour emissions distribution from the landfill, two hypotheses were assumed: a) the emission source was placed in the centre of the landfill; and b) the emissive surface was set conservatively equal to the total area of the landfill.

The flow rate of odorous substances was modelled as in a landfill ordinary conditions, which correspond to a constant emission factor equal to 8 o.u. $/ \mathrm{m}^{2} \mathrm{~s}$ (Sironi et al. 2005). The meteorological data of the monitoring station called AM 289-Capodichino of the year 2007 were used as input conditions. In particular, they included hourly values of the wind direction, the wind speed, the temperature, the stability classes and the mixing heights. Specifically, the meteorological data set was provided to CALPUFF in ISCST3 data format, as suggested by Trinity Consultants Incorporated (1996).

In addition, two odour concentrations equal respectively to $1.5 \mathrm{o} . \mathrm{u} . / \mathrm{m}^{3}$ and $3.0 \mathrm{o.u} . / \mathrm{m}^{3}$ on the $98^{\text {th }}$ percentile hourly basis (Environment Agency UK 2002), were considered as a reference Odour Thresholds (OTs) for the assessment of odour dispersion from the landfill, called respectively OT1 and OT2, and the Number Of Exceedances (NOEs) over the two thresholds considered were also valuated.

To optimize the FOPS, the first quarter (i.e. first three months of year 2007) of the meteorological data was chosen as "training data" input set, while the remaining quarters as "validation data" input set.

\section{Results}

For each SOR, NOEs over the two considered thresholds (OTs) were computed both for the emission rates controlled by FOPS and by considering emission rates without applying any mitigation actions. In addition, the concentrations at the $95^{\text {th }}$ and $98^{\text {th }}$ percentile were also reported. The results obtained are presented in Tables 2, 3, and 4 for SOR-1, SOR-2 and SOR-3, respectively. As shown in them, most of the odour concentrations obtained exceeded both 1.5 o.u. $/ \mathrm{m}^{3}$ (OT1) and 3.0 o.u. $/ \mathrm{m}^{3}$ (OT2) thresholds. Moreover, the concentration at the $98^{\text {th }}$ percentile was always above OT1 and, for the SOR-3, also above OT2. From Tables 2-4 it is possible to observe that the FOPS system allowed for a considerable reduction of NOEs in all the sensitive receptors. In particular, for the 1.5 o.u. $/ \mathrm{m}^{3}$ threshold (OT1), the NOEs decreased by about $97 \%$ in SOR-1, about $96 \%$ in SOR-2 and about $51 \%$ in SOR-3. Moreover, after the application of FOPS, there were no NOEs in SOR-1 nor SOR-2 for the threshold 3.0 o.u. $/ \mathrm{m}^{3}$ (OT2), while a decrease of about $90 \%$ in SOR-3 was observed. 
It is worth highlighting that the odour concentrations in SOR-1 and in SOR-2 (Table 2 and Table 3, respectively) were significantly lower than OT1 by using FOPS (results obtained both at the $98^{\text {th }}$ and at the $95^{\text {th }}$ percentile). While, as illustrated in Table 4, SOR-3 is the sensitive centre with the highest NOEs, consequently it resulted to be more exposed to the smell harassment, also because it is the closest point to the emissive source. Although the FOPS system allowed for a significant reduction of the total NOEs, the concentrations at the $98^{\text {th }}$ percentile and at the $95^{\text {th }}$ percentile are not always lower than the thresholds considered. In the last quarter of the validation set, instead, the concentrations at the $95^{\text {th }}$ percentile obtained were lower than the $1.5 \mathrm{o} . \mathrm{u} . / \mathrm{m}^{3}$ threshold (OT1).

Table 2 SOR-1 results both in case of active fuzzy controller (FOPS) and without it $\left(\mathrm{C}_{\text {Cost }}\right)$

Table 3 SOR-2 results both in case of active fuzzy controller (FOPS) and without it $\left(\mathrm{C}_{\text {Cost }}\right)$

Table 4 SOR-3 results both in case of active fuzzy controller (FOPS) and without it $\left(\mathrm{C}_{\text {Cost }}\right)$

Table 5 Reduction index $\left(\mathrm{I}_{\mathrm{r}}\right)$ and activation index $\left(\mathrm{I}_{\mathrm{a}}\right)$ for the three SORs

In addition, the odour concentrations obtained over time computed via CALPUFF software simulations were also compared with the odour concentration values obtained by using ISCST3-BREEZE model, which was utilized in a previous study (Di Nardo et al. 2013b). Such comparison showed higher values in the computational domain via using CALPUFF.

Finally, a further evaluation was carried out by comparing simulation results exceeding OT1 obtained with and without using the active fuzzy system for each SOR. For this purpose statistical box plots for a more effective representation of the statistical data were utilised whose results are presented in Figures 5-7. In particular, for each month, the odorous concentrations were analysed statistically, reporting the values of: the mean, the median, and the $5^{\text {th }}, 25^{\text {th }}, 75^{\text {th }}$ and $95^{\text {th }}$ percentiles of the odour concentrations computed during the whole simulation interval time and the corresponding NOEs. For each SOR, data were reported both by activating the proposed active fuzzy controller application (FOPS) and as raw data, allowing a more direct and useful analysis.

In Fig. 5, the simulations results for SOR-1 for the whole year 2007, by comparing the mean values of odour concentrations obtained both with FOPS and without (Fig.5a and Fig. 5b, respectively) are represented. As shown, an overall significant reduction of all monthly mean values can be depicted when using the fuzzy system. In particular, the maximum values in the figures is the odour mean in April ( $4^{\text {th }}$ month), where with FOPS a decrement from 2.44 o.u. $/ \mathrm{m}^{3}$ (Fig. 5a) to 1.62 o.u. $/ \mathrm{m}^{3}$ (Fig. 5b) was observed. It is worth underlining that in some cases, as reported in the Fig. 5b, no exceedances occurred in some months (i.e., January, February, May, June, July and December), while in other months, such as March (1 NOE), April (1 NOE), August (1 NOE), September (2 NOEs) and November (2 NOEs), NOEs are always lower than three and the box plots indicate only mean value of odorous concentrations. As displayed, for SOR-1, only October exceeded OT1 for three times, consequently it is demonstrated a significant influence of FOPS in NOEs reduction (Fig. 5b). 
Fig. 5 (a) Box plot of the odour concentrations for SOR-1 without FOPS. (b) Box plot of the odour concentrations for SOR-1 with FOPS. For each box plot, the mean, the median, and the $5^{\text {th }}, 25^{\text {th }}, 75^{\text {th }}$ and $95^{\text {th }}$ percentiles of the odour concentrations computed during the whole simulation interval time and the corresponding NOEs are reported

In Fig. 6, the same comparison is represented for SOR-2. Results showed a significant modification of the shape of each box plot and a reduction of both mean and median concentrations via using FOPS. As it is possible to observe, all the percentiles computed with FOPS are significantly lower than the corresponding data obtained without the mitigation actions supposed. However, in some cases, the odour reduction did not prevent to exceed OT1 and OT2 (such as the maximum values of $95^{\text {th }}$ percentile occurring in July where the initial value was 6.81 o.u. $/ \mathrm{m}^{3}$ and with the fuzzy system it reduced only to 3.43 o.u. $/ \mathrm{m}^{3}$ ). In addition, by analysing SOR-2 results in Fig. 6a and Fig. 6b, the maximum values of the mean in May decreases with FOPS from 4.48 o.u. $/ \mathrm{m}^{3}$ (Fig. 6a) to 2.04 o.u. $/ \mathrm{m}^{3}$ (Fig. 6b) very similarly to the behaviour of the median in April, which decreased from 4.28 o.u. $/ \mathrm{m}^{3}$ (Fig. 6a) to 1.82 o.u. $/ \mathrm{m}^{3}$ (Fig. 6 b).

Fig. 6 (a) Box plot of the odour concentrations for SOR-2 without FOPS. (b) Box plot of the odour concentrations for SOR-2 with FOPS. . For each box plot, the mean, the median, and the $5^{\text {th }}, 25^{\text {th }}, 75^{\text {th }}$ and $95^{\text {th }}$ percentiles of the odour concentrations computed during the whole simulation interval time and the corresponding NOEs are reported

Finally, Fig. 7 shows the comparison for SOR-3. As depicted, also in this case, a reduction of all monthly values of the concentrations mean with the fuzzy system was achieved. In particular, without any mitigation actions, the maximum value of the mean of January is equal to $2.84 \mathrm{o.u} . / \mathrm{m}^{3}$ (Fig. 7a) but with FOPS this value is void as there are no exceedances (Fig. 6b).

Similarly to SOR-1, also for SOR-3, the NOEs achieved with FOPS were significantly lower than the operational condition without applying any mitigation actions. Indeed, only in October and November, NOEs value is higher than 3 while for the other months, the exceedances were only 1 for most months and equal to 2 for March and September, while null for January, February and April.

Fig. 7 (a) Box plot of the odour concentrations for SOR-3 without FOPS. (b) Box plot of the odour concentrations for SOR-3 with FOPS. . For each box plot, the mean, the median, and the $5^{\text {th }}, 25^{\text {th }}, 75^{\text {th }}$ and $95^{\text {th }}$ percentiles of the odour concentrations computed during the whole simulation interval time and the corresponding NOEs are reported

To conclude, in Table 5, the Reduction Index, $I_{r}$ and the Activation Index, $I_{a}$, are stated. A further evaluation of the differences between the two indexes allowed to identify additional effective activations to avoid to exceed both odour thresholds in all sensitive centres. The best values of $I_{r}$ resulted equal to $70 \%$, and it was obtained in SOR1, while $I_{a}$ was equal to $60 \%$; corresponding to the activation of the FOPS system for about 5,200 hours in a year. 


\section{Conclusions}

In the present study, an optimal Fuzzy System, FOPS, . a real-time decision-making support tool for early warning able to mitigate annoying odorous emissions deriving from waste landfills was proposed. The FOPS was implemented in a MATLAB framework and CALPUFF software was used to predict the atmospheric dispersion of the odorous emissions over time.

The FOPS was applied to a real case study of a MSW landfill, called "Cava del Cane", located in the Metropolitan Park of Naples hills. For the case study, three Sensitive Odour Receptors (SORs) were taken into account and two Odour Thresholds (OTs) describing respectively odour annoyance and nuisance of the receptors exposed were compared with the odour concentrations obtained via software dispersion simulations. The meteorological data are used as input data to estimate the odour concentration in the computational domain via Calpuff and then used inFOPS. An improvement of the model could be achieved by considering additional input variables as: temperature, atmospheric stability class etc.

Results showed that the FOPS fuzzy system allowed for a substantial reduction of the concentrations in all SORs considered in the area, with a number of FOPS activation higher than 50\%. Moreover, the use of FOPS endorsed a drastic reduction of the number of exceedances of the stated OTs in all SORs analysed. In particular, both for SOR-1 and SOR-3, a significant reduction was achieved, by attesting a good effectiveness of such mitigation system. In addition, the optimization of the active fuzzy system by using a GA algorithm led to a significant improvement of it, different to the system previously proposed by the authors. The approach used showed how fundamental is formalizing the management of the empirical rules adopted, and integrating those into an automated active decision support system. In this way, it was possible to consider different changeable parameters (i.e. weather conditions) in a specific rules framework that can represent the core of management activities of a MSW landfill.

\section{References}

Aatamila M, Verkasalo PK, Korhonen MJ (2010) Odor annoyance near waste treatment centers: A populationbased study in Finland. J Air Waste Manag Assoc 60:412-418.

doi: 10.3155/1047-3289.60.4.412

Akbari V, Rajabi MA, Chavoshi SH, Shams R (2008) Landfill Site Selection by Combining GIS and Fuzzy Multi Criteria Decision Analysis, Case Study: Bandar Abbas, Iran. World Appl Sci J 3:39-47

Bortone I, Carrillo S, Nardo A Di, et al (2012) Mitigation of the Odorous Impact of a Waste L andfill Located in a Highly Urbanized Area. Ital Assoc Chem Eng 28:229-234 . doi: 10.3303/CET1228039

Brattoli M, de Gennaro G, de Pinto V (2011) Odour Impact Monitoring for Landfills. In: Kumar S (ed) Integrated Waste Management - Volume I., InTech, pp 507-520.Caramia, M. and Dell'Olmo, P. (2008) Multi-Objective Management in Freight Logistics. Springer, London.

Caramia, M. and Dell'Olmo, P. (2008) Multi-Objective Management in Freight Logistics. Springer, London.

Cavallo A, Di Nardo A, De Maria G, Di Natale M (2013) Automated Fuzzy Decision and Control System for reservoir management. J Water Supply Res Technol - AQUA 62:189-204 . doi: 10.2166/aqua.2013.046

Chang Y-J, Lin M-D (2013) Compromising economic cost and air pollutant emissions of municipal solid waste 
management strategies by fuzzy multiobjective optimization model. J Air Waste Manag Assoc 63:712-723

Chen L, Hoff S, Cai L, et al (2009) Evaluation of wood chip-based biofilters to reduce odor, hydrogen sulfide, and ammonia from swine barn ventilation air. J Air Waste Manag Assoc 59:520-530 . doi: 10.3155/10473289.59.5.520

Chianese S, Loipersböck J, Malits M, et al (2015) Hydrogen from the high temperature water gas shift reaction with an industrial $\mathrm{Fe} / \mathrm{Cr}$ catalyst using biomass gasification tar rich synthesis gas. Fuel Process Technol 132:39-48 . doi: 10.1016/j.fuproc.2014.12.034

Chung YC, Ho KL, Tseng CP (2007) Two-stage biofilter for effective NH3 Removal from Waste Gases Containing High Concentrations of H2S. J Air Waste Manag Assoc 57:337-347 . doi: $10.1080 / 10473289.2007 .10465332$

Daskalopoulos E, Badr O, Probert SD (1997) Economic and Environmental Evaluations of Waste Treatment and Disposal Technologies for Municipal Solid Waste. Appl Energy 58:209-255. doi: 10.1016/S03062619(97)00053-6

De Feo G, De Gisi S, Williams ID (2013) Public perception of odour and environmental pollution attributed to MSW treatment and disposal facilities: A case study. Waste Management, 33: 974-987. doi.org/10.1016/j.wasm an.2012.12.016.

Di Nardo A, Di Natale M, Guida M, Musmarra D (2013a) Water Network Protection from Intentional Contamination by Sectorization. Water Resour Manag 27:1837-1850 . doi: 10.1007/s11269-012-0133-y

Di Nardo A, Santonastaso GF, Immacolata B, et al (2013b) A Fuzzy Early Warning System To Mitigate the Odorous Substances Emitted From a Waste Landfill. In: T.D. L (ed) Proceedings of 13th International Conference on Environmental Science and Technology (CEST 2013)

Dokas IM, Karras DA, Panagiotakopoulos DC (2009) Fault tree analysis and fuzzy expert systems: Early warning and emergency response of landfill operations. Environ Model Softw 24:8-25 . doi: 10.1016/j.envsoft.2008.04.011

Dokas IM, Karras DA, Panagiotakopoulos DC (2008) An Efficient Fuzzy Expert System Architecture for Landfill Operation Reliability Management. J Intell Syst 17:72-90 . doi: 10.1515/JISYS.2008.17.1-3.73

Dokas IM, Panagiotakopoulos DC (2006) A knowledge acquisition process to analyse operational problems in solid waste management facilities. Waste Manag Res 24:332-344 . doi: 10.1177/0734242X06063349

Drew GH, Smith R, Gerard V, et al (2007) Appropriateness of selecting different averaging times for modelling chronic and acute exposure to environmental odours. Atmos Environ 41:2870-2880 . doi: 10.1016/j.atmosenv.2006.09.022

Dubois D, Prade H (1980) Fuzzy sets and systems: theory and applications

Environment Agency UK (2002) Integrated Pollution Prevention and Control (IPPC) Horizontal Guidance for Odour Part 1 - Regulation and Permitting

EPA-Ireland (2000) Landfill manuals Landfill site design

Erto A, Andreozzi R, Di Natale F, et al (2009) Experimental and isotherm-models analysis on TCE and PCE adsorption onto activated carbon. Chem Eng Trans 17:293-298 . doi: 10.3303/CET0917050

Fabbri B, Gherardi S, Giberti A, et al (2014) Sensing of gaseous malodors characteristic of landfills and waste 
treatment plants. J Sensors Sens Syst 3:61-67 . doi: 10.5194/jsss-3-61-2014

Fan YR, Huang GH, Huang K, et al (2014) A generalized fuzzy integer programming approach for environmental management under uncertainty. Math Probl Eng 2014:72-86 . doi: 10.1155/2014/486576

Fang J, Zhang H, Yang N, et al (2013) Gaseous pollutants emitted from a mechanical biological treatment plant for municipal solid waste: Odor assessment and photochemical reactivity. J Air Waste Manag Assoc 63:1287-1297 . doi: 10.1080/10962247.2013.822439

Goldberg DE (1989) Genetic algorithms in search, optimization, and machine learning reading. MA AddisonnWisley, USA

Hobbs SE, Longhurst P, Sarkar U, Sneath RW (2000) Comparison of dispersion models for assessing odour from municipal solid wastes. Waste Manag Res 18:420-428 . doi: 10.1034/j.1399-3070.2000.00155.x

Hriberšek M, Samec N, Ravnik J, Zadravec M (2011) Numerical Simulations of Wind Induced Particle Contamination in Gypsum Landfill Surroundings. Environ Model Assess 16:479-489 . doi: 10.1007/s10666011-9255-5

Karatza D, Prisciandaro M, Lancia A, Musmarra D (2010) Sulfite oxidation catalyzed by cobalt ions in flue gas desulfurization processes. J Air Waste Manag Assoc 60:675-680 . doi: 10.3155/1047-3289.60.6.675

Khalsa SK (2009) A Fuzzified Approach for the Prediction of Fault Proneness and Defect Density. World Congr Eng I:218-223

Li YP, Huang GH, Nie XH, Nie SL (2008) An inexact fuzzy-robust two-stage programming model for managing sulfur dioxide abatement under uncertainty. Environ Model Assess 13:77-91 . doi: 10.1007/s10666-006$9077-\mathrm{z}$

Lou Z, Wang M, Zhao Y, Huang R (2015) The contribution of biowaste disposal to odor emission from landfills. J Air Waste Manag Assoc 65:479-484 . doi: 10.1080/10962247.2014.1002870

Meišutovič-Akhtarieva M, Marčiulaitienė E (2017) Research on Odours Emitted from Non-Hazardous Waste Landfill Using Dynamic Olfactometry. Proceedings of "Environmental Engineering” 10th International Conference, Vilnius Gediminas Technical University Lithuania, 27-28 April 2017. eISSN 2029-7092 / eISBN 978-609-476-044-0. doi: https://doi.org/10.3846/enviro.2017.034

Panigrahi DP, Mujumdar PP (2000) Reservoir operation modelling with fuzzy logic. Water Resour Manag 14:89109. doi: 10.1023/A:1008170632582

Poor N, Pollman C, Tate P, et al (2006) Nature and magnitude of atmospheric fluxes of total inorganic nitrogen and other inorganic species to the Tampa Bay watershed, FL, USA. Water Air Soil Pollut 170:267-283 . doi: $10.1007 / \mathrm{s} 11270-006-3055-6$

Qin XS, Huang GH, Liu L (2010) A Genetic-Algorithm-Aided Stochastic Optimization Model for Regional Air Quality Management under Uncertainty. J Air Waste Manage Assoc 60:63-71 . doi: 10.3155/10473289.60.1.63

Scire JS, Strimaitis DG, Yamartino RJ (2000) A user's guide for the CALPUFF dispersion model

Shill PC, Hossain MA, Hossain MK, et al (2012) Design and Implementation of an Effective Fuzzy Logic Controller based on Quantum Inspired Evolutionary Algorithm. J Comput 7: . doi: 10.4304/jcp.7.3.586-596

Singh AP, Vidyarthi AK (2008) Optimal allocation of landfill disposal site: A fuzzy multi-criteria approach. Iran 
J Environ Heal Sci Eng 5:25-34

Sironi S, Capelli L, Céntola P, et al (2005) Odour emission factors for assessment and prediction of Italian MSW landfills odour impact. Atmos Environ 39:5387-5394 . doi: 10.1016/j.atmosenv.2005.05.023

Sugeno M (1985) Industrial Applications of Fuzzy Control. 269

The MathWorks Inc. (2004a) Fuzzy logic toolbox, User's Guide. Natick, MA

The MathWorks Inc. (2004b) Optimization toolbox, User's Guide. Natick, MA

U.S.EPA (1995a) Air Emissions from Municipal Solid Waste Landfills - Background Information for Final Standards and Guidelines

U.S.EPA (1995b) User's Guide for the Industrial Source Complex (ISC3) Dispersion Models

U.S.EPA (1995c) A User's Guide for the CALPUFF Dispersion Model

Wang S, Huang GH (2013) Interactive fuzzy boundary interval programming for air quality management under uncertainty. Water Air Soil Pollut 224: . doi: 10.1007/s11270-013-1574-5

Wang X, Huang G (2015) Impacts Assessment of Air Emissions from Point Sources in Saskatchewan, Canada A Spatial Analysis Approach. Environ Prog Sustain Energy 34:304-313 . doi: 10.1002/ep.11948

Xu Y, Huang G (2015) Development of an Improved Fuzzy Robust Chance-Constrained Programming Model for Air Quality Management. Environ Model Assess 20:535-548 . doi: 10.1007/s10666-014-9441-3

Young PJ, Parker A (1983) The identification and possible environmental impact of trace gases and vapours in landfill gas. Waste Manag Res 1:213-226 . doi: 10.1177/0734242X8300100126

Zhang Y, Huang G (2010) Fuzzy robust credibility-constrained programming for environmental management and planning. J Air Waste Manag Assoc 60:711-721 . doi: 10.3155/1047-3289.60.6.711 